\title{
Mortality from non-communicable diseases in South Africa, 1997-2009
}

\author{
Eric O. Udjo ${ }^{1}$ and Pinky Lalthapersad-Pillay ${ }^{2}$ \\ ${ }^{1}$ Bureau of Market Research, University of South Africa, PO Box 392 UNISA 0003, Pretoria, South \\ Africa, Tel: 012- 429 3326, Fax: 012-429 6225 Email: udjoe@unisa.ac.za \\ ${ }^{2}$ Department of Economics, University of South Africa, PO Box 392 UNISA 0003, Pretoria, \\ South Africa
}

\begin{abstract}
There are estimates of the magnitude of non-communicable disease deaths for less developed countries but little is known about the dynamics in Africa. The continent is undergoing unprecedented growth of the elderly population. This raises the need to examine mortality from non-communicable diseases. This study examines mortality attributable to non-communicable diseases in South Africa during the period 1997-2009. The data used are the death records for the period 1997-2009. Standardised crude death rates were computed. Logistic regression was used to examine the odds of dying from non-communicable diseases controlling for covariates. The results indicate that cardiovascular diseases had the highest death rate as immediate or underlying causes of death during the period 1997-2009. Sex, level of education and the type of industry of employment as well as the smoking status of the deceased were found to be significantly associated with the odds of dying from non-communicable diseases in South Africa.
\end{abstract}

Keywords: Mortality, Non-communicable diseases, ageing, causes of death, South Africa

\section{Résumé}

On estime l'ampleur des décès attribuables aux maladies non transmissibles pour les pays moins développés, mais on connaît mal la dynamique en Afrique. Le continent connaît une croissance sans précédent de la population âgée. Cela déclenche la nécessité d'examiner la mortalité due aux maladies non transmissibles. Cette étude examine la mortalité attribuable aux maladies non transmissibles en Afrique du Sud au cours de la période 1997-2009. Les données utilisées sont les registres de décès pour la période 1997-2009. Normalisé les taux bruts de mortalité ont été calculés. Régression logistique a été utilisée pour examiner les chances de mourir de maladies non transmissibles, tenant compte de covariables. Les résultats indiquent que les maladies cardiovasculaires avaient le taux de mortalité plus élevé comme causes immédiates ou sousjacente de la mort au cours de la période 1997-2009. Sexe, niveau d'éducation et le type d'industrie, de l'emploi ainsi que l'usage du tabac du défunt se sont avéré pour être significativement associés.

Mots clés: mortalité, maladies Non transmissibles, vieillissement, causes de décès, l'Afrique du Sud

\section{Introduction}

\section{Problem Statement}

There is a large amount of literature on mortality from non-communicable diseases in the more developed countries but less so in the less developed countries. Chronic non-communicable diseases account for over half of global deaths (Ghaffar et al., 2004; Ebrahim and Smeeth, 2005; Capilheira et al. 2008; Nabel et al, 2009). According to the World Health Organisation (20II), noncommunicable diseases (NCD) constituted about $63 \%$ of all deaths globally in 2008 with $20 \%$ of the NCD deaths occurring in high-income populations. It is predicted that by 2020 NCD will be causing 601 seven out of every 10 deaths in developing countries (Boutayab and Boutayab, 2005). It is clear from these figures that mortality from NCD is gaining increasing prominence and poses challenges for health care provision especially in the less developed countries.

Although estimates of NCD deaths have been provided for less developed countries (see Boutayeb and Boutayab, 2005, Miranda et al., 2008; Stevens, $20 \mathrm{II}$ ), little is known about the dynamics of NCD in Africa. The less focus on NCD in Africa is partly due to: (I) lack of data either due to the absence, or limited coverage of vital registration in the continent; (2) the emergence of the HIV/AIDS epidemic in the 
1980s thus shifting attention from communicable diseases (CD) in general to specific forms of infectious diseases associated with HIV/AIDS. Although the impact of HIV/AIDS on morbidity and mortality in Africa cannot be overemphasized, the continent is at the same time undergoing unprecedented growth of the elderly population (see Nabalamba and Chikoko, 20I I). Rapid growth of the elderly population in specific African countries raises the need to examine mortality from chronic non-communicable diseases in these countries.

\section{Contextualising Non-communicable Diseases}

The prominence of mortality due to NCD is usually is commonly associated with the epidemiologic transition which states that during the transition a shift occurs in mortality and disease patterns whereby pandemics of infection are progressively displaced by degenerative and man-made diseases as the leading causes of death (Omran and Omran, 1982). Demographic and social factors have been identified to be responsible for the emergence of chronic diseases in different settings (Ebrahim and Smeeth 2005; Yang et al., 2008). The demographic factors pertain to the transition from high to low fertility and mortality resulting in ageing of the population as life expectancies increase. Thus, as longevity increases, NCD gains increasing prominence. Furthermore, as longevity increases there is a rapid increase in man-made diseases due to changes in life style behaviour. Thus, demographic transition and life style behaviour reinforce increase in NCD.

South Africa has been undergoing fertility and mortality transition. The crude birth rate declined from about 40 per thousand in the 1970s to its current level of about 25 per thousand (Udjo, 2006a). Crude death rate declined from about 12 per thousand in the 1970s to about 9 per thousand in the early 1990s (Udjo, 2006a). This demographic transition has resulted in the ageing of South Africa's population. According to an estimate, the percentage of the elderly population (persons aged 65 years and over) increased from about $5 \%$ in 1970 to $7 \%$ in 2006 (Udjo, 2006a).

\section{Objectives}

The purpose of this study is to examine levels, trends and determinants of NCD mortality in South Africa during the period 1997-2009. Specifically, the study examines: (I) trends in the contribution of NCD relative to $C D$, as immediate or underlying cause of death during the period 1997-2009; (2) levels and trends in death rates from NCD and broad categories during the period 1997-2009; (3) determinants of NCD mortality.

\section{Data}

South Africa has a long history of vital registration dating back to 1910 though during the apartheid era, the system was fragmentary and coverage was more limited (Khalfani, Zuberi, Bah and Lehohla, 2005). In a study, Udjo (2006b) estimated that completeness of registration of female deaths in South Africa increased from about $74 \%$ in 1997 to about $84 \%$ in 2006 while for males, it increased from about $84 \%$ in 1997 to about $92 \%$ in 2006 . Coverage of vital registration is therefore high in South Africa.

The sources of data for this study therefore, are the death records for the period 1997-2009 (these were the available records at the time of this study. Death records constitute an important source for examining leading causes of death in a population as information on causes of death may not be meaningfully collected in surveys and censuses. The death notification forms in South Africa, among other variables, contain the medical certification of cause of death that includes the immediate and underlying causes.

\section{Coding, compilation and publishing of death records}

Statistics South Africa has the legal mandate to process and publish vital statistics based on deaths reported to the Department of Home Affairs (Statistics South Africa, 2005). The processing includes capturing, cleaning and coding of the causes of death using the $10^{\text {th }}$ revision of the International Classification of Diseases (ICD-10). Statistics South Africa derives the underlying causes of death using "Automated Classification of Medical Entities" developed by the Unites States National Centre for Health Statistics (Statistics South Africa, 2005). The analysis and results presented in this study are based on the ICD-IO coding of the death records undertaken by Statistics South Africa.

\section{Limitations of data}

One of the problems in using death notification records is incompleteness of registration which may be due to incomplete coverage of the entire population by the system or failure to register such events, or register them long after the occurrence of the event. As already noted, completeness of vital registration in South Africa is high but not 100 per cent complete. 
Another limitation is misclassification of cause of death. Certain causes of death may be misclassified as deaths due to other causes. For example, AIDS related deaths may be classified as deaths due to other causes. Additionally, multi-morbidity can lead to a severe bias in the declared causes of death. For example, some deaths occurring in the old ages may involve multiple causes which may lead to biases in identifying the true causes of death using ICD classification system. Misclassification of cause of death is more difficult to assess than completeness of death registration. It is not clear whether NCD are more likely to be misclassified than $C D$ overall. However, on the basis of the evaluations on completeness of death registration, the estimated death rates from NCD presented in this study need to be interpreted as lower limits. It would have been useful to examine differences in NCD among the four population groups as well as by rural/urban in South Africa. This was not possible because the publicly available data on causes of death no longer include these variables in the data base.

\section{Definition of NCD}

NCD are diseases that are not transmissible directly or indirectly from one person to the other. According to the ICD-IO classification, the broad categories of these diseases include malignant neoplasms, other neoplasm, diabetes mellitus, endocrine disorders, neuropsychiatric conditions, sense organ diseases, cardiovascular diseases, respiratory diseases, digestive diseases, genitourinary diseases, skin diseases, musculoskeletal diseases, congenital anomalies and oral conditions.

\section{Methods}

Levels and trends: Age standardised death rates Mortality varies with age and crude death rates are sensitive to age structure as they do not take into account variations in age structure of a population. Since the age structure of a population varies over time, it would be misleading to compare crude death rates over time in a population without taking into account the changing age structure. Appropriate comparison of crude death rates should therefore be based on computing age standardised death rates.

The indirect standardisation used for this purpose in this study entailed: (I) defining a standard set of age-specific death rates attributable to NCD either as immediate or underlying cause of death; (2) computing the expected number of cases of NCD on the basis of the standard rates; (3) computing standardised mortality ratios (SMR) as:

$S M R=S / E$

Where $S M R$ is the standardised mortality ratio, $S$ is the standard crude death rate from NCD in the index population, and $E$ is the expected crude death rate from NCD; (4) computing the age standardised crude death rate from NCD as:

$A S C D R=S M R * S$.

Where ASCDR is the age standardised crude death rate from NCD. The age groupings used are 0-14, 15-49, 50-59 and 60 years and over. The index population for the standardised crude death rates was the estimated population of South Africa in 1997 as produced by Udjo (2009).

\section{Determinants of NCD}

A limited number of socio-economic factors are included in the more recent death records of the deceased in South Africa. A logistic regression analyses was carried out to determine which of these factors (explanatory variables) significantly increase or decrease the odds of dying from NCD (dependent variable) if other variables remained constant among persons aged 15 years and over. The relevant demographic, socio-economic and behavioural variables in the death records are sex, education, type of industry of employment of the deceased as well as the smoking status of the deceased. In algebraic terms, the logistic regression model is expressed as

$$
\operatorname{Prob}(N C D)=\frac{1}{1+e^{-\left(B_{0}+B_{1} X_{1}+B_{2} X_{2}+B_{3} X_{3}+B_{4} X_{4}\right)}}
$$

(Hosmer and Lemeshaw, 2000) where

$\operatorname{Prob}(N C D)$ is the probability of a person dying of NCD.

$N C D=\mathrm{I}$ if the immediate or underlying cause of death was NCD;

$N C D=0$ if the immediate or underlying cause of death was not NCD;

$e=$ base of the natural logarithm;

$B_{0}=$ constant;

$B_{1 \ldots 5}=$ estimated regression coefficients corresponding to the independent variables $X_{1} \ldots X_{5}$; where:

$X_{1}=$ Sex: $\quad I=$ male, $0=$ female (reference category); 
$X_{2}=$ Highest education completed (an indicator variable with four categories): none, primary, secondary and tertiary and each category coded I, if the highest level of education was either none, primary or secondary, or 0 otherwise with tertiary as the reference category;

$X_{3}=$ Type of business or industry (an indicator variable with nine categories) coded similarly as in $\mathrm{X}_{2}$, with agriculture together with hunting, forestry and fishing as the reference category.

$X_{4}=$ whether the person was smoker five years ago: $\mathrm{I}=$ yes, $0=$ non-smoker (reference category).

\section{Results}

\section{Levels and Trends in NCD}

\section{Trend in Ratio of NCD to CD}

The ratio of NCD to $C D$ deaths as immediate or underlying cause of death during the period 1997 to
2009 in South Africa is illustrated in Figure I. As seen from the graph, the ratio of the number of NCD to CD deaths was over 1.0 during the period 1997 to 2005 implying that NCD as immediate or underlying cause of death contributed more than $C D$ as immediate or underlying cause of death to overall mortality during the period. It can also be seen from the graph that the ratio of the number of NCD to $C D$ deaths declined during the period despite increasing ageing of the South African population.

It can also be seen from Figure I that there was a slight upward trend in ratio of NCD to $C D$ after 2005 implying that the contribution of NCD to overall mortality in South Africa has been on the increase since 2006.

Figure I: Ratio of NCD to CD deaths as immediate or underlying causes of death, all ages

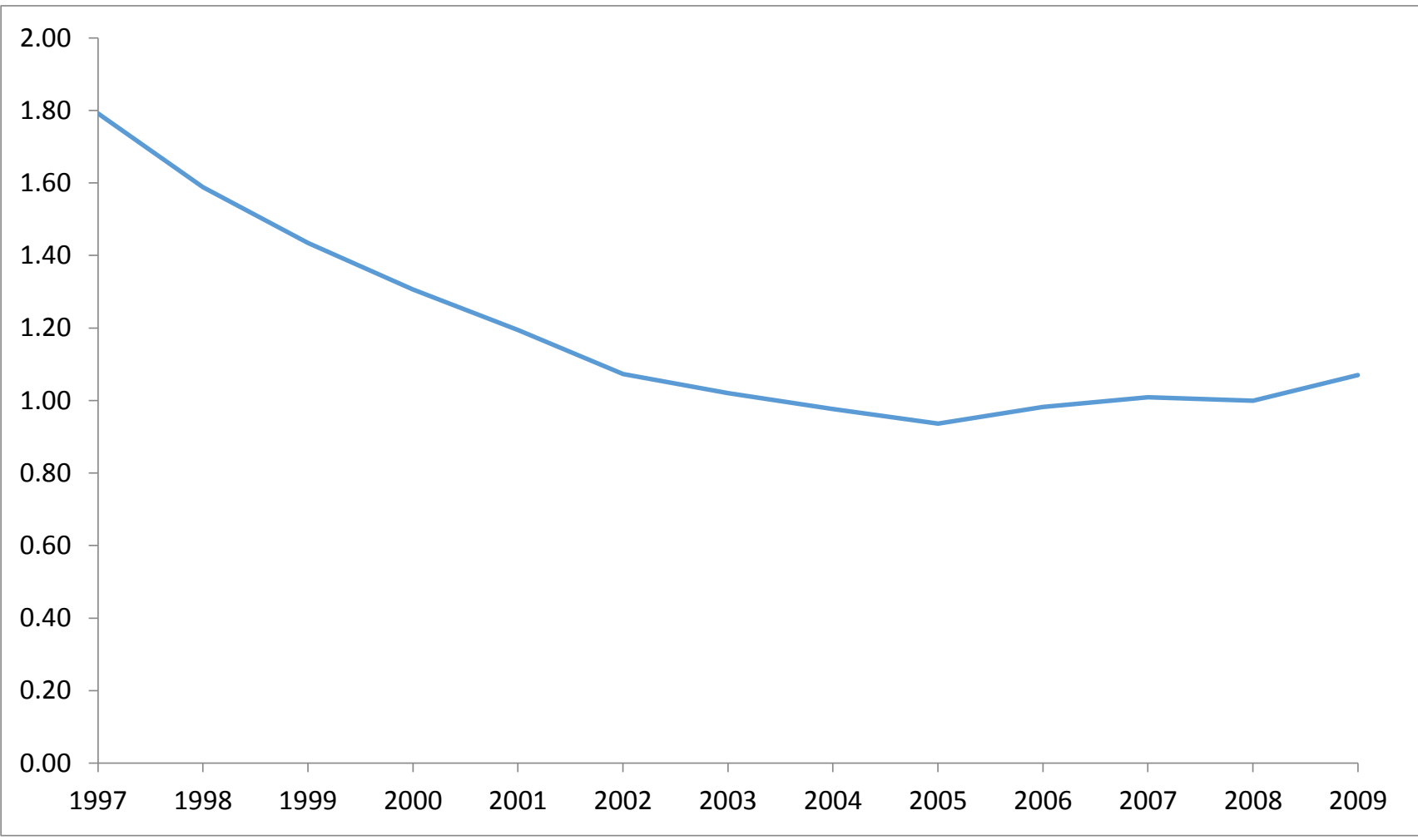

Source: Computed from Statistics South Africa's death records data.

Levels and Trends in Crude Death Rates from NCD as Immediate or Underlying Cause of Death

The absolute numbers of deaths from NCD should increase over time due to population increase. Population ageing in a demographically transitional population should also increase the absolute numbers of deaths in a population as well as alter the age structure of the population. Excess mortality due to AIDS-related death also has an impact on the age structure of populations that experience high levels of HIV prevalence. These conditions are present in South Africa. To control for these factors age standardised crude death rates were computed. The results are shown in Figure 2. The following pattern emerged from the results. 
Figure 2: Age standardised crude deaths rates from NCD, 1997-2009.

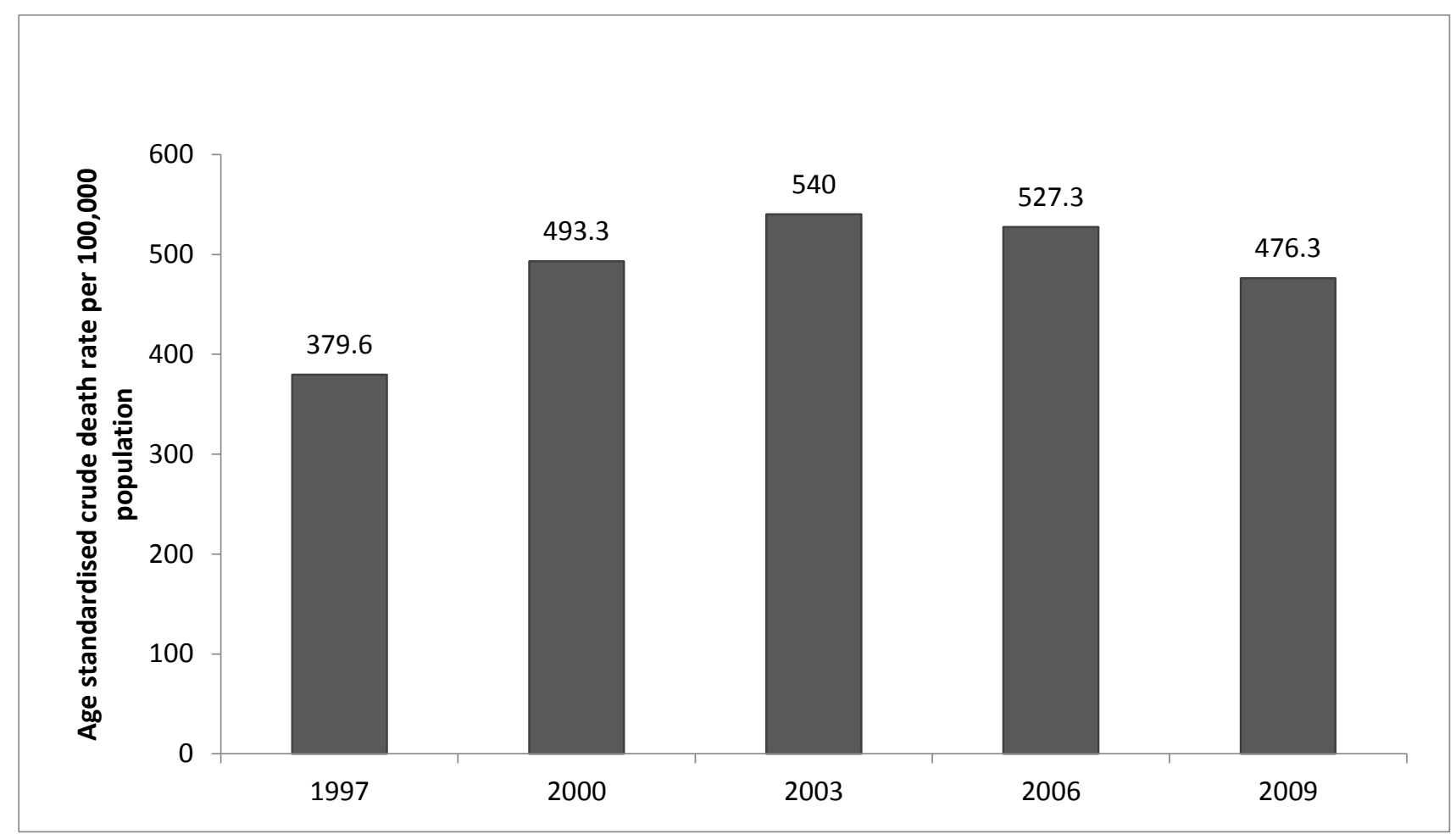

Source: Computed fromStatistics South Africa's death records data

Although the percentage contribution of NCD to total registered deaths declined during the period 1997-2005, standardised crude death rates from NCD as immediate or underlying cause of death increased during the period up to 2003. The estimated standardised crude death rates indicate that while in 1997 the crude death rate from NCD was at least 379 per 100,000 persons in the general population, by 2003 , the rate had increased to at least 540 per 100,000 persons. However, by 2009, it had dropped to 476 per 100,000 persons. The standardised mortality ratios (not shown) suggest that controlling for changes in age structure, the crude death rate from NCD in 2003 was about $42 \%$ higher than the rate in 1997 but by 2009, it was about $25 \%$ higher than the rate in 1997.

\section{Levels and Trends in Crude Death Rates from NCD as Immediate or Underlying Cause of Death by broad categories}

Although examination of the overall magnitude of death rates from NCD is useful, it is also important to examine variation in death rates from NCD by broad categories so that policies and intervention programs can be more focused.

Figure 3 shows that of all the broad categories of NCD, cardiovascular diseases had the highest death rate as immediate or underlying causes of death during the period 1997-2009, while sense organ diseases and congenital anomalies had the lowest death rate during the period among persons aged I5 years and over. For example, while the age standardised crude death rate from cardiovascular diseases was at least 263 per 100,000 among persons aged 15 years and over in 2009, the corresponding crude death rate from sense organ diseases and congenital anomalies were less than I.0 per 100,000 
Figure 3: Age standardised crude death rates among persons aged I 5 years and over by NCD broad categories

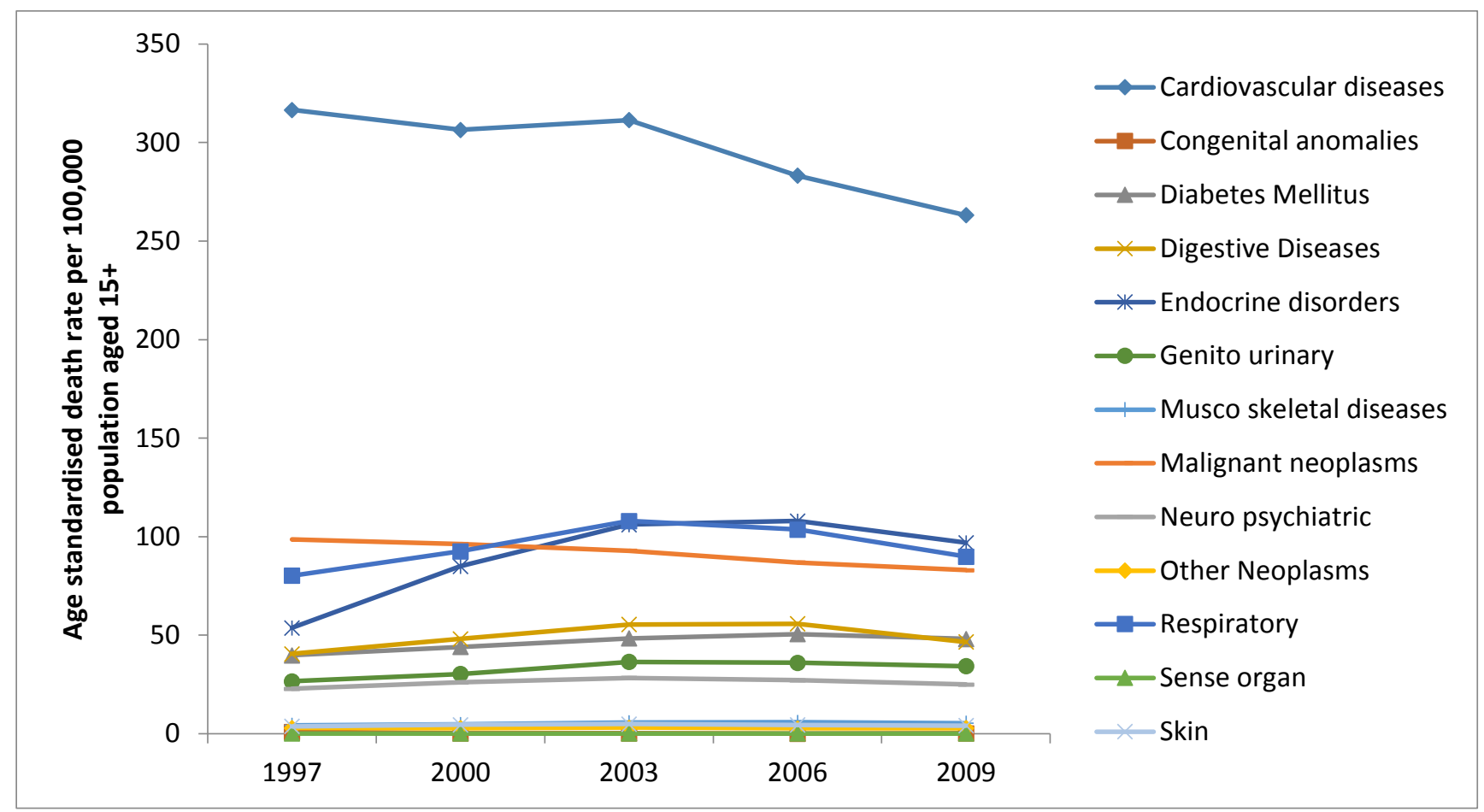

Source: Computed from Statistics South Africa's death records data.

Regarding their trends, the death rate from cardiovascular diseases and malignant neoplasms declined during the period 1997-2009. This may partly be a reflection of better management of the diseases. Death rates from respiratory diseases and other neoplasms were more or less stable during the period but death rate from diabetes mellitus, endocrine disorders, neuropsychiatric conditions and digestive diseases increased slightly in varying degrees during the period.

\section{Determinants of NCD}

As indicated above, a limited set of demographic (sex), socio-economic (education and industry) and behavioural (smoking status) characteristics of the deceased are available in the more recent death records. A logistic regression model was applied to the 2009 death records to examine the relationship between these factors and the odds of dying from NCD among persons aged I 5 years and above.
The results indicate that sex, level of education and the type of industry of employment as well as the smoking status of the deceased are significantly associated with the odds of dying from NCD among persons aged 15 years and above (Table I). Specifically, females have a significantly lower odd $(p<0.000)$ of dying from NCD than males controlling for other factors. Persons with tertiary level of education have significantly higher odd of dying from NCD than persons with lower or no education controlling for other factors $(p<0.000)$. Also, persons who worked in mining, and quarrying, construction as well as whole sale and retail trade, restaurants have significantly higher odd of dying from NCD than persons who worked in agriculture, hunting, forestry and fishing industry. This may partly be associated with differences in the nature of the working environment. Lastly, as expected, smoking significantly increases the odds of dying from NCD controlling for other factors $(p<0.05)$. 
Table I: Logistic regression of NCD among persons aged I5 years and over by socio-economic and behavioural factors

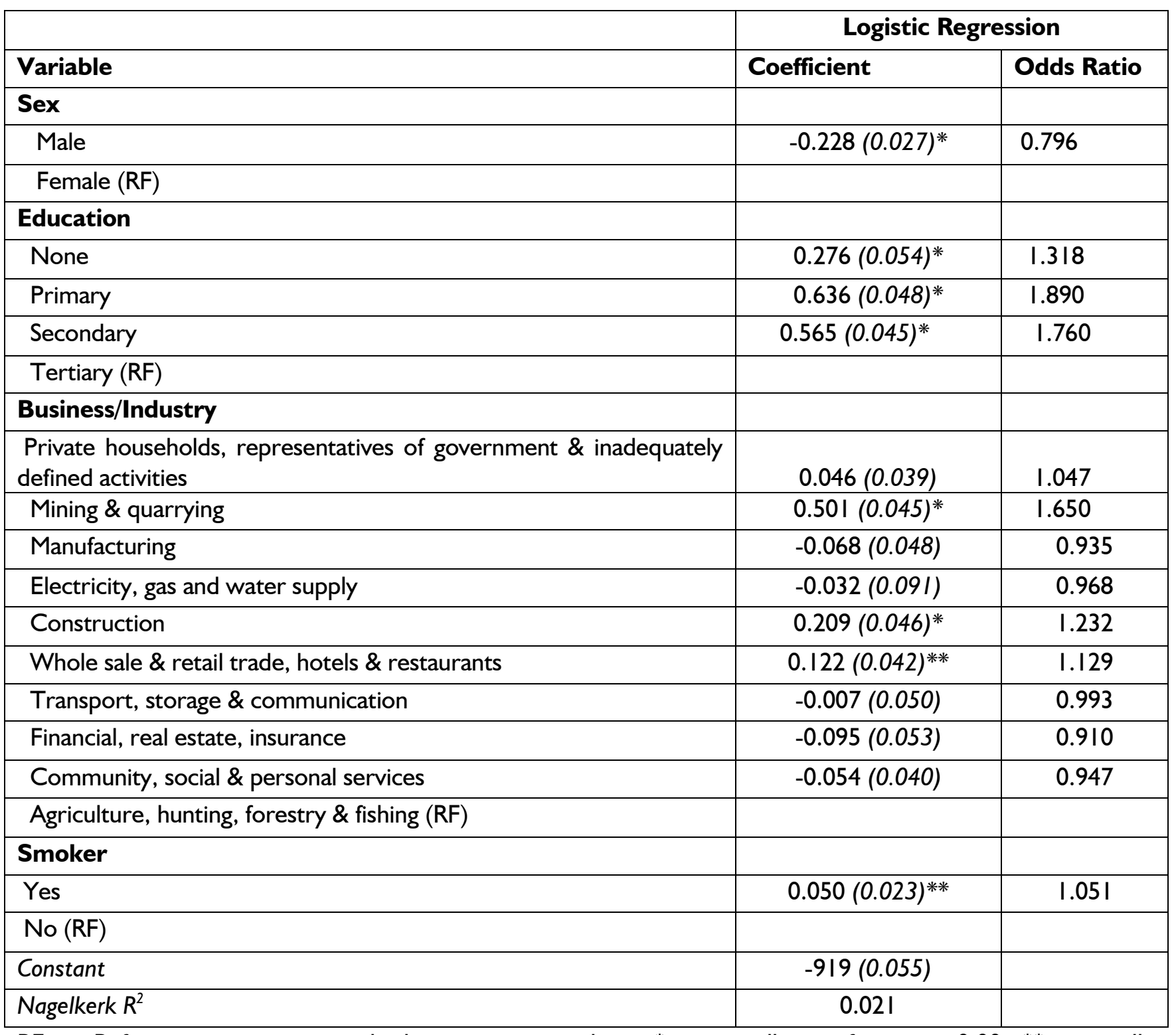

$\mathrm{RF}=$ Reference category, standard error in parenthesis * statistically significant, $\mathrm{p}<0.00$, **statistically significant, $\mathrm{p}<0.05$.

Source: Computed from Statistics South Africa's death records data.

\section{Discussion and conclusion}

Estimates from the World Health Organisation suggest that death rates from NCD in Southern African countries are either comparable to or higher than death rates from NCD in the European region even though the latter has a much older age structure than Southern Africa. For example while the age standardised crude death rate in the European region was 590 per 100,000 population in 2004 , for the same period, it was 594, 580, 513 , and 706 per 100,000 population respectively in
Botswana, Lesotho, Namibia and Swaziland in the same period (World Health Organisation, 2010).

This study shows that there was a slight rising trend in the contribution of NCD to overall mortality after 2005. As the demographic transition in South Africa becomes more marked and ageing of the population progresses, death rates from NCD are likely to increase in the future. NCD is therefore likely to pose a greater challenge to health care provision in the future in South Africa. Cardiovascular diseases had the highest death rate 
as immediate or underlying causes of death during the period 1997-2009.

Rising trends in death rates from NCD in various countries have been linked by several studies to changes in behavioural life style as the main risk factor. These factors include changing diet resulting in overweight and obesity, decreased physical activity, alcohol abuse and smoking. Boutayeb and Boutayeb (2005), for example, observed that despite different levels of cardiovascular diseases, diabetes, cancer and chronic respiratory diseases in developing countries, a common denominator is the risk factors namely, tobacco, alcohol, high blood pressure, diet and physical inactivity at different levels. Capilheira et al. (2008) detected a high prevalence of the main risk factors for chronic diseases among persons aged 15-69 years in Brazil as smoking, overweight/obesity, and physical inactivity. The increase in the proportion of overweight and obese in China between 1992 and 2002 was linked to reduced physical activity (Yang et al., 2008). It is not possible to link these factors directly to the emergence and trend in NCD in South Africa due to lack of data. However, the limited data indicate that sex, level of education and the type of industry of employment of the deceased and the smoking status of the deceased are significantly associated with the odds of dying from NCD among persons aged 15 years and above in South Africa.

Mufunda (2006) observed that, in Africa, the available limited resources are committed to $C D$ such as HIV/AIDS, tuberculosis, and malaria whose prevalence data and impact on economic development are much more noticeable, leaving the increase in the burden from NCD unchecked. Unwin et al (200I) argued that since NCD and HIVrelated diseases tend to affect the economically active population both should be tackled.

A number of approaches have been suggested for the management of NCD. These include rationalized NCD primary care model developed by Coleman et al. (1998) and the Chronic Care Model (CCM) developed by Epping-Jordan et al (2004). Coleman et al.'s model is suitable for a rural setting and has been applied successfully in a resource-poor setting in South Africa. The components of the model include (I) creating a clinic-held register with demographic, diagnostic and management details; (2) developing diagnostic and management protocols with treatment algorithms including the training of nurses in their use; (3) incorporating education and self-care in management protocols; (4) prioritization of patience convenience, introduction of repeat prescription, rationalization of drug ordering and monitoring of adherence and side-effects. EppingJordan et al.'s model is probably more appropriate to a more developed urban setting. The components of the model include self-management support, delivery system design, decision support and clinical information systems. Elements of these models may be adapted by policy makers in the management of NCD in South Africa.

The limitations of this study pertain to the data utilised and include: (I) incompleteness of death registration; (2) certain causes of death may have been mis-classified thus the results in this study are probably lower limits of the death rates from NCD in South Africa. As completeness of death registration improves, further studies are required to quantify the magnitude of death rates from NCD in the country. The relationship of risk factors and NCD in South Africa has not been systematically explored and was not possible in the present study due to lack of data. The estimated low value of the Nagelkerke $R^{2}$ of 0.02 I (which is less than 0.5 ) from the logistic regression suggests that other explanatory variables may also be important (unobserved heterogeneity) in the odds of death from NCD in South Africa. The inclusion of more information on the death records especially behavioural would enhance further research and inform program intervention in the management of NCD in South Africa.

\section{Acknowledgement}

The authors gratefully acknowledge Statistics South Africa for providing access to the data used in this study. The views expressed in this paper however, are those of the authors and do not necessarily reflect those of Statistics South Africa.

\section{References}

Boutayab, A., Boutayab, S., 2005. "The burden of non-communicable diseases in developing countries". International Journal for Equity in Health 4:I-8

Capilheira, M.F., Santos, I.S., Azevedo Jr, M.R., Reichert, F.F., 2008. "Risk factors for chronic non-communicable diseases and the CARMEN initiative: a population-based study in South of Brazil". Cadernos de Saude Publica 24: I-5

Coleman, R., Gill, G., Wilkinso, D., 1998. "Noncommunicable disease management in resourcepoor settings: a primary care model from South 
Africa". Bulletin of the World Health Organisation, 76(6):633-639

Ebrahim, S., Smeeth, L., 2005. "Non-communicable diseases in low and middle-income countries: a priority of a distraction". International Journal of Epidemiology 34:96I-966

Epping-Jordan, J.E., Pruitt, S.D., Bengoa, R., Wagner, E.H., 2004. "Improving the quality of health care for chronic conditions". Quality and Safety in Health Care, 13:299-305

Ghaffar, A., Reddy, K.S., Singhi, M., 2004. "Burden of non-communicable diseases in South Asia". British Medical Journal 328:807-810

Hosmer, D.W., Lemeshow, S., 2000. Applied logistic regression. New York: John Wiley and Sons

Khalfani, A.K., Zuberi, T., Bah S., Lehohla, P.J., 2005. Population statistics. In, Zuberi, T., Sibanda, A., Udjo, E., (eds). The demography of South Africa. New York: M. E. Sharpe

Miranda, J., Kinra, S., Casas, J.P., David, Smith, G., Ebrahim, S. 2008. "Non-communicable diseases in low-middle-income countries: context, determinants and health policy". Tropical Medical Journal of International Health, 13(10): 12251234.

Mufunda, J., Chatora, R., Ndambaluwa, Y., Nyarango, P., Kosia, A., Chifamba, J., Filipe, A., Usman, A., Sparks, V.A. 2006. "Emerging noncommunicable disease epidemic in Africa: preventive measures from the WHO regional office for Africa”. Ethnicity and Disease, 16:521526

Nabalamba, A, and Chikoko, M, 20II. "Aging population challenges in Africa". AFDB I(I): I18.

Nabel, E.G, Stevens, S., Smith, R., 2009. "Combating chronic diseases in developing countries". Published Online: www. The Lancet.com, June 2009.

Omran, A.R., 1982. Epidemiologic transition theory. In, International Encyclopedia of Population. Ross JA (ed) I:172,183. New York: The Free Press.

Population Reference Bureau, 2009. World population data sheet 2009. Published Online: www.prb.org.

Statistics South Africa. 2005. Mortality and causes of death in South Africa, 1997-2003: Findings from death notification. Pretoria: Statistics South Africa.
Stevens, P. 20II. The challenges of noncommunicable diseases in developing countries: lessons from HIV and global health. New York:CMPI.

Udjo, E.O., 2006a. "Demographic impact of HIV/AIDS on the young and elderly populations in South Africa". Journal of Intergenerational Relations 4:23-39.

Udjo, E.O., 2006b. "Estimation of mortality from vital registrations in South Africa". Current HIV Research 4:469-474

Udjo, E.O., 2008. "A re-look at recent statistics on mortality in the context of HIV/AIDS with particular reference to South Africa". Current HIV Research 6:|43-I5|

Udjo, E.O., 2009. Population estimates for South Africa by magisterial district and province, 2008. Bureau of Market Research, Research Report No. 380, University of South Africa, Pretoria.

UNAIDS. 20I0. Global report on the AIDS epidemic 2010. Geneva: UNAIDS

Unwin, N., Setel, P., Rashid, S., Mugusi, F., et al., 200I. "Non-communicable diseases in subSaharan Africa: where do they feature in the health research agenda?" Bulleting of the World Health Organisation, 79(10):947-953.

World Health Organisation. 2010. Estimated age standardised death rate, non-communicable diseases. Published online: www.who.org/infobase

World Health Organisation. 20II. Global status report on non-communicable diseases 2010. Geneva: WHO.

Yang, G., Kong, L., Zhao, W., et al. 2008. "Emergence of chronic non-communicable diseases in China". The Lancet 372:1697-I 705.

\section{Authors Contributions}

Contribution of authors: First author: Study conceptualisation and technical analysis. Second Author: Study conceptualisation and review of gaps in knowledge in non-communicable diseases studies. 